\title{
Original
}

\section{Ponytail headache (external-traction headache): prevalence, characteristics and relationship with migraine}

\author{
Larissa Paes Barreto (iD Carolina Reis (iD) Daniella Araújo de Oliveira (iD Marcelo Moraes Valença
}

Neurology and Neurosurgery Unit, Hospital das Clínicas, Federal University of Pernambuco, Recife, Pernambuco, Brazil

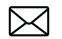

Marcelo Moraes Valença

mmvalenca@yahoo.com.br

Edited by

Mario Fernando Prieto Peres

\author{
Abstract \\ Introduction \\ Despite its frequent occurrence, external-traction headache (previously named as "ponytail \\ headache") is scarcely documented in the literature.
}

\section{Objective}

In the present study we set out to estimate the prevalence of ponytail headache and its relationship with migraine.

\section{Methods}

One hundred and thirty women (27.7 \pm 11.1 years of age), 108 of them reported a previous history of primary headache [81/130 (62.3\%) migraine or probable migraine and $27 / 130(20.8 \%)$ non-migraine headache; 22/130 (16.9\%) did not report any previous episode of headache], were requested to wear a ponytail for 60 minutes, removing it only in case of pain. When pain occurred, it was recorded for the latency between the placement of the ponytail and the onset of the pain, its duration and characteristics. The women also filled out a questionnaire on previous headache episodes.

\section{Results}

During the 60 minute-period, 52/130 (40\%) women had ponytail headache elicited by the experiment. There was a higher prevalence of ponytail headache in those who reported previous episodes of primary headache [48/108 (44.4\%)], compared to those who did not [4/22 $(18.2 \%)](p=0.022)$. The migraineurs had more ponytail headache than non-migraneurs [39/81 $(48.2 \%)$ versus $9 / 27(33.3 \%), p=0.180]$ with a positive history of primary headache and they also had more than those without [4/22 (18.2\%)] $(p=0.012)$. The group of women with migraine also presented more ponytail-induced headache than non-migraineurs combined with the group of individuals without a previous history of headache [13/49 $(26.5 \%)$, OR 2.57, 95\% Cl 1.19$5.55 ; p=0.015]$. Migraine-like episodes were trigged in $3 / 52$ (5.8\%) by the experiment, all three migraineurs. The latency time for the beginning of ponytail headache during the experiment was $21.5 \pm 15.4 \mathrm{~min}$ and the duration was 76.0 $\pm 159.3 \mathrm{~min}$.

\section{Conclusion}

The prevalence of ponytail headache in our study was $40 \%$ and was statistically higher in migraineurs. 


\section{Introduction}

D espite of its frequent occurrence, the headache caused by wearing a tight ponytail (ponytail headache, currently named as external-traction headache)' is scarcely documented in the medical literature. ${ }^{2}$ In a cross-sectional study, Blau ${ }^{2}$ observed a $53.8 \%$ prevalence of ponytail headache among the 90 women interviewed.

The simple act of loosening the hair in order to relieve the headache probably makes people think that it does not merit any particular attention. Ponytails, however, are part of the everyday lives of a large number of women, being in some cases worn compulsorily as part of their professional uniforms or optionally during athletic performance. In addition, Headaches may be triggered by a ponytail without the individual realizing that the ponytail may be the cause of the headache. In very young girls a ponytail might trigger a headache, and this is frequently overlooked by the parents. For this reason, we believe that it may have a high negative impact on the quality of life of some individuals. Based on the theory that ponytail use may cause peripheral and central sensitization in the nociceptive system of migraineurs, resulting in a state of hyperexcitation of the pathways of pain control systems $\mathrm{s}^{3.5}$, we hypothesized that ponytail headache may be more prevalent in migrainous women and may contribute to the maintenance and exacerbation of this condition.

The objective of this study was to estimate the frequency of ponytail headache in women to clinically characterize this type of headache and to investigate its relationship with migraine. To this end, we used an experimental model to trigger the headache, requesting the subjects to wear a ponytail continuously for 60 minutes.

\section{Methods}

A group of 130 women, between 15 and 60 years of age, from the Metropolitan Region of Recife, were the subjects of an experiment in which they had to wear a ponytail continuously on the top of their head for 60 minutes. The study was approved by the Ethics Committee of CCS/UFPE. If they experienced any pain, they informed the researcher immediately and the ponytail was removed, even before the end of the 60-minute period. The researcher recorded the time of latency between the ponytail placement and the onset of the pain. Subsequently, the subject also informed the researcher of the duration and characteristics of the pain, when it was felt, its location (unilateral, bilateral or diffused), quality (pulsating, stabbing, constrictive or continuous), intensity (mild, moderate or severe) and whether it was worsened by physical activities such as walking, domestic tasks, climbing and going down stairs, or whether it was accompanied by nausea and/or vomiting, photophobia (whether light bothered more intensely during the pain episode), and phonophobia (whether noise bothered more intensely during the pain episode). All subjects also informed the researcher regarding any previous history of headache, in order to be classified as carriers of migraine or non-migraine sufferers, based on the criteria established by ICHD 3rd edition ${ }^{6}$.

The results were analyzed using the Graph Pad Prism 5.0 software. The data were presented as mean \pm standard deviation. The Kolmogorov-Smirnov test with a $95 \%$ confidence interval was used for verifying the type of distribution of the variables studied. The-MannWhitney and Kruskal-Wallis tests were used for non-normal distributions. The chi-square $\left(\chi^{2}\right)$ test was applied to evaluate the categorical variables, according to the expected frequencies. The level of significance considered was $p<0.05$.

\section{Results}

Our sample was composed of 130 female volunteers, between the ages of 15 to 60 years $(27.7 \pm 11.1) .108$ of them reported a previous history of primary headache according to the diagnostic criteria (ICHD 3rd edition) $)^{6}$ suggested by the Headache International Society: 81/130 (62.3\%) with episodes of headache attacks compatible with migraine or probable migraine [10/81 (12.4\%) with aura]; $27 / 130(20.1 \%)$ were classified as non-migraine sufferers, and $22 / 130$ (16.9\%) did not report any previous episode of headache.

During the 60 minute-period, 52/130 (40\%) women had ponytail headache elicited by the experiment. There was a higher prevalence of ponytail headache in those who reported previous episodes of primary headache [48/108 $(44.4 \%)]$, compared to those who did not [4/22 (18.2\%)] $\left(p=0.022, \chi^{2}\right)$. The migraineurs had more ponytail headache than non-migraneurs [39/81 (48.2\%) versus 9/27 (33.3\%)] with a positive history of primary headache and they also had more than those without [4/22 (18.2\%); OR 2.57, 95\% Cl 1.19-5.55; $p=0.012 \mathrm{X}^{2}$ ) (Figure 1). The group of women with migraine also presented more ponytail-induced headache than non-migraineurs combined with the group of individuals without a previous history of headache [13/49 (26.5\%), $\left.\mathrm{p}=0.015 \mathrm{X}^{2}\right]$.

Migraine-like episodes were trigged in 3/52 (5.8\%) by the experiment, all three migraineurs. 
The age was statistically higher in the group which had ponytail headache than in the group that did not present headache during the experiment $(31.4 \pm 13.1$ versus 25.2 \pm 8.9 , respectively; $p=0.006$, Mann-Whitney test). The latency time for the beginning of ponytail headache during the experiment ranged from 16 seconds to $58.7 \mathrm{~min}(21.5$ $\pm 15.4 \mathrm{~min})$. The duration of the pain ranged from 15 seconds to 13 hours $(76.0 \pm 159.3 \mathrm{~min})$. There were no statistical significant differences in the latency periods for the beginning of ponytail headache among the three different groups studied $(21.2 \pm 13.8 \mathrm{~min}$ in migraineurs; $21.7 \pm$ $16.8 \mathrm{~min}$ non-migraineurs with a history of headache; 21.8 \pm 18.6 min with no previous history of headache; $p=0.980$, Kruskal-Wallis test).

There were likewise no statistical differences in the duration of ponytail headache among the three different groups analyzed (136.0 \pm 229.0 min migraineurs; $34.0 \pm 46.0$ min nonmigraineurs with a history of headache; $18.4 \pm 23.3 \mathrm{~min}$ with no previous history of headache; $p=0.316$, Kruskal-Wallis test). The characteristics of the headache are shown in Table 1. In addition 16/52 (30.7\%) with ponytail headache reported that the pain was exacerbated by physical activities, 5/52 (9.6\%) that it was accompanied by photo- and phonophobia, and $11 / 52(21.2 \%)$ that the episode was accompanied by nausea and/or vomiting.

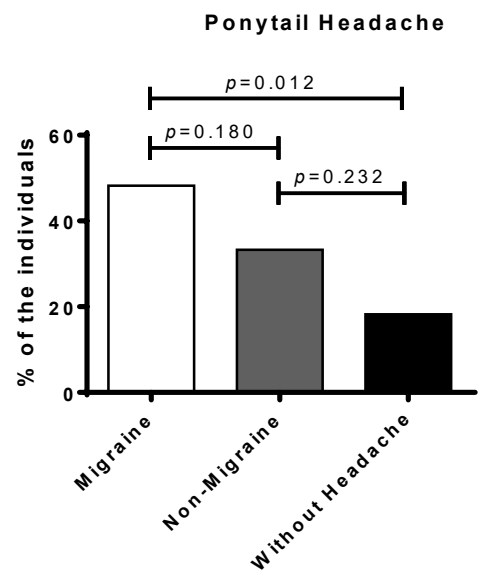

Figure 1. Frequency of ponytail-induced headache.Individuals with probable migraine were considered migraineurs. Chi-square test.

\section{Discussion}

The high prevalence of ponytail-induced headache in our sample (40\%), albeit lower than that reported by Blau' in his study (53.8\%), draws our attention to the importance of considering this type of headache in the investigation of headaches in women, especially among those who have to wear a ponytail everyday as an integral part of their uniform.
In a prospective study with 82 policemen in Rio de Janeiro, Krymchantowski and coworkers ${ }^{7}$ analyzed the complaints of headache clearly triggered by the wearing of a helmet. The pain remitted in all the patients after the removal of the helmet. As we know, a helmet is compulsorily worn as a part of the uniform. Among patients with a previous history of migraine, they found a prevalence of $30.5 \%$ of this type of headache triggered by the continuous wearing of the helmet. ${ }^{7}$

In our group, subjects with a previous history of migraine had headache episodes that fulfilled the diagnostic criteria for migraine attack elicited by the experiment, clearly indicating that the wearing of ponytail type of accessories on the hair may, in migraineurs, trigger migraine episodes. Thus, the mechanical pulling of the hair leads to the onset of a migraine-like attack. In migraine, the ability of external factors to trigger headache attacks is well known. ${ }^{8.11}$ Furthermore, surgeries were developed considering anatomical sites' existence as a possible anatomical triggering of headache attacks. ${ }^{12 \cdot 15}$

Table 1. Characteristics of the headache attacks observed in the 52 volunteers who developed ponytail-induced headache during the 60 minute-period of the experiment

\begin{tabular}{|c|c|c|c|c|}
\hline & $\begin{array}{l}\text { Migraine } \\
(\mathrm{n}=39)\end{array}$ & $\begin{array}{l}\text { Non-Migraine } \\
(n=9)\end{array}$ & $\begin{array}{l}\text { Without Headache } \\
\qquad(n=4)\end{array}$ & Total $(n=52)$ \\
\hline \multicolumn{5}{|l|}{ Laterality } \\
\hline Unilateral & 7 (17.9\%) & 3 (33.3\%) & $0(0.0 \%)$ & 10 (19.2\%) \\
\hline Bilateral & 32 (82.1\%) & $6(66.7 \%)$ & $4(100.0 \%)$ & 24 (46.2\%) \\
\hline \multicolumn{5}{|l|}{ Quality } \\
\hline Pulsatile & $12(30.8 \%)$ & $1(11.1 \%)$ & $1(25.0 \%)$ & $14(26.9 \%)$ \\
\hline Non pulsatile & 27 (69.2\%) & 8 (88.9\%) & $3(75.0 \%)$ & 38 (73.1\%) \\
\hline \multicolumn{5}{|l|}{ Severity } \\
\hline Mild & $22(56.4 \%)$ & 7 (77.8\%) & $4(100.0 \%)$ & 33 (63.5\%) \\
\hline Moderate & 15 (38.5\%) & 1 (11.1\%) & $0(0.0 \%)$ & $16(30.8 \%)$ \\
\hline Severe & $2(5.1 \%)$ & $1(11.1 \%)$ & $0(0.0 \%)$ & $3(5.8 \%)$ \\
\hline $\begin{array}{l}\text { Worsens with } \\
\text { effort }\end{array}$ & $16(41.0 \%)$ & $0(0.0 \%)$ & $0(0.0 \%)$ & $16(30.8 \%)$ \\
\hline $\begin{array}{l}\text { Nauseas/ } \\
\text { Vomiting }\end{array}$ & 5 (12.8\%) & $0(0.0 \%)$ & $0(0.0 \%)$ & $5(9.6 \%)$ \\
\hline $\begin{array}{l}\text { Photo- or } \\
\text { Phonophobia }\end{array}$ & 9 (23.1\%) & 2 (22.2\%) & $0(0.0 \%)$ & $11(21.2 \%)$ \\
\hline Aura & $2(5.1 \%)$ & $0(0.0 \%)$ & $0(0.0 \%)$ & 2 (3.9\%) \\
\hline
\end{tabular}

The highest prevalence of ponytail headache may be explained by the theory of peripheral and central sensitization of the nociceptive system of migraineurs. ${ }^{2,3}$

The ponytail may trigger migraine attacks in a similar way observed with external compression headaches caused by headwear that may induce long-term pressure on the fore head or scalp. Thus, the clinician should advise the migrainous patient to avoid wearing a tight ponytail, as well 
as other pressuring devices (i.e. glasses, helmet, tight hats, tiara, googles, etc.). $6,7,16$

The systematic and continuous use of a ponytail may have a high negative impact on a woman's quality of life, causing ponytail headache or acting as a trigger for migraine like headache episodes that can be incapacitating. The cessation of the use of a ponytail is the most effective treatment in these cases.

\section{Conclusion}

The prevalence of ponytail-induced headache in our sample was $40 \%$, being more prevalent in migraineurs.

Conflicts of Interest: The authors declare no conflicts of interest. Author contributions statement

MMV designed this study, wrote, interpreted the data, and revised this manuscript; DAO interpreted the data and revised this manuscript; $L P B$ and $C R$ carried out the experiment with the volunteers and revised this manuscript.

Larissa Paes Barreto

https://orcid.org/0000-0001-9805-4813

Carolina Reis

https://orcid.org/0000-0001-9863-4586

Daniella Araújo de Oliveira

https://orcid.org/0000-0002-6013-978X

Marcelo Moraes Valença

https://orcid.org/0000-0003-0678-3782

\section{References}

1. Valenca MM, de Oliveira DA. The Frequent Unusual Headache Syndromes: A Proposed Classification Based on Lifetime Prevalence. Headache 2016;56:141-152

2. Blau JN. Ponytail headache: a pure extracranial headache. Headache 2004;44:41 1-413

3. Dodick D, Silberstein S. Central sensitization theory of migraine: clinical implications. Headache 2006;46 Suppl 4:S182-191
4. Bendtsen L. Central and peripheral sensitization in tension-type headache. Curr Pain Headache Rep 2003;7:460-465.

5. Burstein R. Deconstructing migraine headache into peripheral and central sensitization. Pain 2001;89:107-110

6. Headache Classification Committee of the International Headache Society (IHS) The International Classification of Headache Disorders, 3rd edition. Cephalalgia 2018;38:1-21 1

7. Krymchantowski A, Barbosa JS, Cvaigman M, et al. Helmetrelated, external compression headache among police officers in Rio de Janeiro. MedGenMed 2004;6:45

8. Holsteen KK, Hittle M, Barad M, et al. Development and Internal Validation of a Multivariable Prediction Model for Individual Episodic Migraine Attacks Based on Daily Trigger Exposures. Headache 2020;60:2364-2379

9. Onderwater GL, van Oosterhout WPJ, Schoonman GG, et al. Alcoholic beverages as trigger factor and the effect on alcohol consumption behavior in patients with migraine. Eur J Neurol 2019;26:588-595

10. Tai MS, Yap JF, Goh CB. Dietary trigger factors of migraine and tension-type headache in a South East Asian country. J Pain Res 2018;11:1255-1261

11. Silva-Neto RP, Peres MF, Valenca MM. Odorant substances that trigger headaches in migraine patients. Cephalalgia 2014;34:14-21

12. Raposio E, Bertozzi N. Trigger Site Inactivation for the Surgical Therapy of Occipital Migraine and Tension-type Headache: Our Experience and Review of the Literature. Plast Reconstr Surg Glob Open 2019;7:e2507

13. Vincent $A$, van Hoogstraten WS, Maassen Van Den Brink A, et al. Extracranial Trigger Site Surgery for Migraine: A Systematic Review With Meta-Analysis on Elimination of Headache Symptoms. Front Neurol 2019;10:89

14. Seyed Forootan NS, Lee M, Guyuron B. Migraine headache trigger site prevalence analysis of 2590 sites in 1010 patients. J Plast Reconstr Aesthet Surg 2017;70:152-158

15. de Ru J. More comments on migraine trigger site decompression surgery: focus on frontal headache. Headache 2015;55:702706

16. Rahmani Z, Kochanek A, Astrup JJ, et al. Helmet-induced headache among Danish military personnel. Scand J Public Health 2017;45:818-823 